\title{
Güncel Veriler Ișığıında COVID-19 ve Renin Anjiyotensin Aldosteron Sistemi İlişkisi
}

\author{
The Relation Between COVID-19 and Renin Angiotensin Aldosterone System in the Light of \\ Current Literature
}

\section{${ }^{1}$ İmdat Eroğlu ${ }_{\mathbb{D}},{ }^{1}$ Oğuz Abdullah Uyaroğlu,${ }^{1}$ Gülay Sain Güven}

${ }^{1}$ HacettepeÜniversitesi Tıp Fakültesi, İç Hastalıkları Anabilim Dalı Ankara, Türkiye

Correspondence: İmdat EROĞLU- HacettepeÜniversitesi Tıp Fakültesi, İç Hastalıkları Anabilim Dalı Ankara, Türkiye e-mail: i.eroglu.1903@gmail.com

Received: 23.06 .2020

Accepted: 04.08.2020

Online published: 04.08 .2020

\section{Özet}

Aralık 2019'da Çin'de etiyolojisi bilinmeyen pnömoni vakaları bildirilmiș olup daha önce insanlarda tespit edilmemiş yeni bir coronavirusun hastalığa neden olduğu tespit edilmiştir. 2002 yılında salgın yapan SARS-CoV virusuna olan benzerliğinden dolayı SARS-CoV-2 olarak adlandırılmıș, virusun yol açtığı klinik hastalığa da "coronavirus hastalığı-2019 (coronavirus disease - 2019, COVID-19)" adı verilmiştir. Hastalığın patofizyolojisi üzerine yapılan ilk çalışmalarda SARS-CoV-2'nin hücreye giriş reseptörü olarak Anjiyotensin Dönüştürücü Enzim2 (ACE2)'yi kullandığı saptanmıştır. Hastalığın Renin Anjiyotensin Aldosteron Sistemi (RAAS) blokerlerinin sıklıkla kullanıldığı hasta gruplarında (hipertansiyon, kardiyovasküler hastalıklar) daha sık saptandığı ve daha ağır seyrettiğinin görülmesi RAAS blokeri olarak kullanılan Anjiyotensin Dönüştürücü Enzim İnhibitörleri(ACEI) ve Anjiyotensin Reseptör Blokörlerinin (ARB) kullanımı ile ilgili endişelere yol açmıştır. COVID-19 pandemisinin başından itibaren bilim dünyasında bu konu ile ilgili birçok farklı görüş bildirilmiş, çalışmalar yapılmış ve yapılmaya devam etmektedir. Bu yazıda, COVID-19 ve RAAS arasındaki ilişki ve COVID-19 hastalarında ACEI/ARB kullanımının potansiyel etkileri güncel literatür eşliğinde gözden geçirilmiştir.

Anahtar Kelimeler: COVID-19; Anjiyotensin Dönüştürücü Enzim, ACE, Renin Anjiyotensin Aldosteron Sistemi, RAAS

\section{Abstract}

In December 2019, pneumonia cases of unknown etiology reported in China. A new coronavirus not previously detected in humans has been found to cause disease. The virus was named SARS-CoV-2 because of the similarity to the epidemic SARS-CoV virus in 2002. The clinical disease caused by the virus was called coronavirus disease-2019 (coronavirus disease - 2019, COVID-19). In the first studies on the pathophysiology of the disease, it was found that SARS-CoV-2 used Angiotensin-Converting Enzyme 2 (ACE2) as the cell entry receptor. The disease has been observed to be more frequent and severe in patient groups (hypertension, cardiovascular diseases) whom Renin Angiotensin Aldosterone System (RAAS) blockers are frequently used. This situation has led to concerns about the use of Angiotensin-Converting Enzyme Inhibitors (ACEI) and Angiotensin Receptor Blockers (ARB). Since the beginning of the COVID-19 pandemic, many different opinions about this issue have been reported. Studies have been done and continue to be carried out. In this article, the relationship between COVID-19 and RAAS and the potential effects of ACEI / ARB use in COVID-19 patients are reviewed in the light of current literature.

Keywords: COVID-19; Angiotensin-Converting Enzyme; ACE; Renin Angiotensin Aldosterone System; RAAS ture, Osmangazi Journal of Medicine, 2021;43(1): 86-93 Doi: 10.20515 / otd. 756606 


\section{Giriş}

Aralık 2019'da Dünya Sağlık Örgütü Çin Ülke Ofisi etiyolojisi bilinmeyen pnömoni vakaları bildirmiş, 7 Ocak 2020'de daha önce insanlarda tespit edilmemiş yeni bir coronavirus'un hastalığa neden olduğu tespit edilmiştir. Başlangiçta 2019-nCoV olarak isimlendirilen yeni coronavirus, salgının ilerleyen dönemlerinde 2002 yılında salgın yapan SARS (Şiddetli Akut Solunum Sendromu) virusuna (SARS-CoV) olan benzerliğinden dolayı SARS-CoV-2 olarak adlandırılmış, virusun yol açtığ klinik hastalığa da "coronavirus hastalığı-2019 “(coronavirus disease - 2019, COVID-19) adı verilmiştir (1).

COVID-19 hastalığının ileri yaş ve / veya hipertansiyon, diabetes mellitus, kardiyovasküler hastalıklar, kronik akciğer hastalıkları, kronik böbrek hastalığı ve obezite gibi komorbiditesi olan kişilerde daha sık görüldüğü ve daha ciddi seyrettiği bildirilmiştir (2).

Hastalığın patofizyolojisi üzerine yapılan ilk çalışmalarda SARS-CoV-2'nin hücreye giriş reseptörü olarak Anjiyotensin Dönüştürücü Enzim2 (ACE2)'yi kullandığ1 saptanmıştır (3). Hastalığın Renin Anjiyotensin Aldosteron Sistemi (RAAS) blokerlerinin sıklıkla kullanıldığ 1 hasta gruplarında (hipertansiyon, kardiyovasküler hastalıklar) daha sık ve ağır seyrettiğinin görülmesi RAAS blokeri olarak kullanılan Anjiyotensin Dönüştürücü Enzim İnhibitörleri(ACEI) ve Anjiyotensin Reseptör Blokörlerinin (ARB) kullanımı ile ilgili endişelere yol açmıştır. COVID-19 pandemisinin başından itibaren bilim dünyasında bu konu ile ilgili birçok farklı görüşler bildirilmiş, çalışmalar yapılmış ve yapılmaya devam etmektedir.

Bu yazıda, COVID-19 ve RAAS arasındaki ilişki ve COVID-19 hastalarında ACEI/ARB kullanımının potansiyel etkileri güncel literatür eşliğinde gözden geçirilmiştir.

\section{Coronavirus Ailesi ve SARS-CoV2}

Coronaviruslar tek zincirli, pozitif polariteli, üzerinde dikensi uzantıları olan RNA viruslarıdır. Bu uzantılardan dolayı Latince'de "taç" anlamına gelen "corona" ismini almışlardır. Coronavirusların insanlarda bulunan, insan- dan insana bulaşabilen çeşitli alt tipleri (HCoV-229E, HCoV-OC43, HCoV-NL63 ve HKU1-CoV) bulunmaktadır. İnsanlar arasında dolaşan bu alt türler çoğunlukla soğuk algınlığına sebep olan viruslardır. Bununla birlikte hayvanlarda saptanan birçok coronavirus alt türü mevcuttur ve bu virusların hayvanlardan insanlara geçerek insanlarda ağır hastalık tablolarına neden olabildiği bilinmektedir (4). Coronaviruslar daha önce Orta Doğu Solunum Sendromu (Middle East Respiratory Syndrome, MERS) ve Ağır Akut Solunum Sendromu (Severe Acute Respiratory Syndrome, SARS) gibi daha ciddi pandemilere neden olmuştur. Aralık 2019'da Çin'de görülen ilk vakanın ardından hızla tüm dünyaya yayılan SARS-CoV-2 ise 30 Ocak 2020'de Dünya Sağlık Örgütü tarafından "uluslararası acil halk sağlığı sorunu" ilan edilmiş ve coronavirus ilişkili üçüncü pandemi olmuştur (5).

\section{Angiotensin Dönüşsürü̈cü Enzim 2 (ACE2)}

Bilinen ilk insan ACE homoloğu olan ACE2, Donoghue ve arkadaşları tarafindan keşfedilen metalloproteaz aktiviteli bir transmembran proteindir. ACE ve ACE2 aminoasid dizilimi \%42 oranında benzer olup, her ikisi de angiotensin 1 (Ang1) üzerinde etkisini gösterir. Bir dipeptidaz olan ACE, Ang1'i angiotensin 2 (Ang2)'ye dönüştürürken, bir karboksipeptidaz olan ACE2, Ang1'i angiotensin (1-9) Ang(1-9)'a, Ang2'yi ise angiotensin (1-7) Ang(1-7)'ye dönüştürmektedir (6, 7). Sonuç olarak ACE'nin ürettiği Ang2, ACE2 tarafından katalize edilerek angiotensin metabolizması düzenlenmektedir ( Şekil-1). 


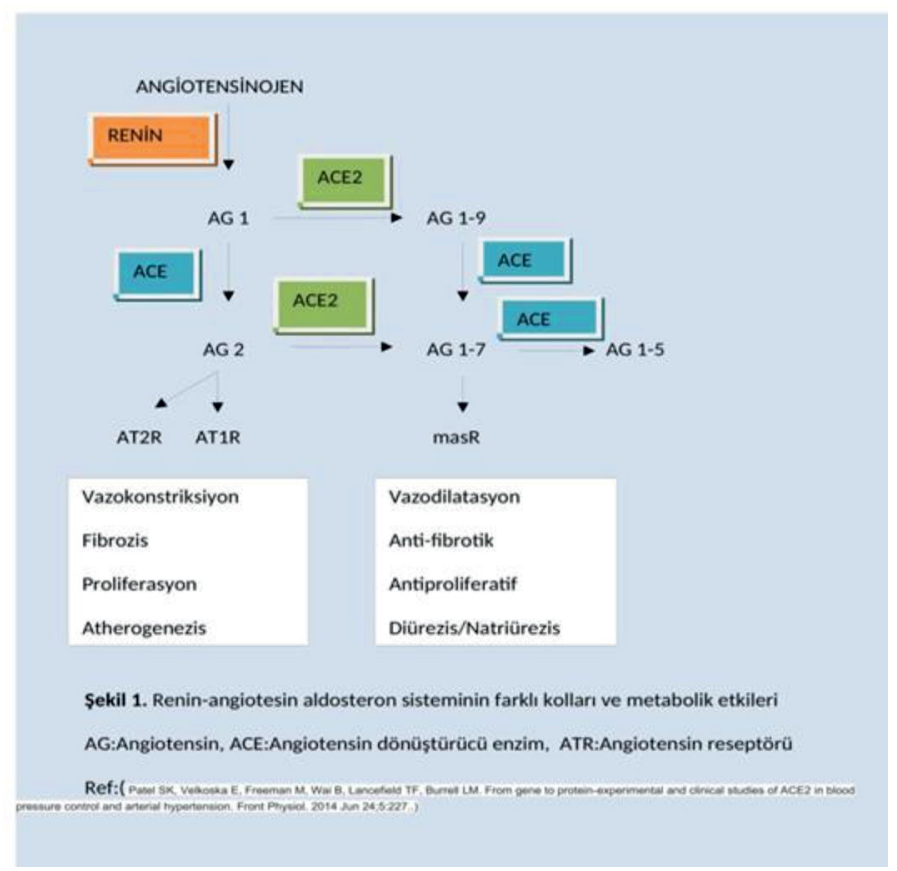

Şekil 1. Renin-angiotesin aldosteron sisteminin farklı kolları ve metabolik etkileri AG:Angiotensin, ACE:Angiotensin dönüştürücü enzim, ATR: Angiotensin reseptörü

Ref:

Farelerde yapılan ilk çalışmalarda, ACE2'nin eksprese olduğu ana dokular testis, böbrek ve kalp olarak saptanmıştır (8). İnsan çalışmalarında karaciğer, akciğer, gastrointestinal sistem ve daha birçok yapıda ACE2 ekspresyonu tespit edilmiştir (9). ACE2'nin temel fizyolojik görevi vazokonstriktör bir ajan olan Ang2'yi; vazodilatör, antifibrotik ve antiinflamatuvar bir peptid olan Ang(1-7)'ye dönüştürmektir ve bu durum proteinin kardiyovasküler sistem üzerindeki etkilerini merak konusu kılmıştır. Zisman ve arkadaşları kalp yetmezliği tanısı alan hastaların ventriküllerinde ACE2 ekspresyonunun arttığını bulmuştur (10). ACE2 geninin baskılandığı fare çalışmalarında, kardiyak kontraktilitede bozukluklar saptanmıştır (11). Miyokard infarktüsü sonrası insan ve fare kalbinde ACE2 ekspresyonunun arttığ1 ve artmış kardiyak ACE2 ekspresyonunun, miyokard infarktüsü sırasında kardiyak fonksiyonu, sol ventrikül duvar hareketini ve kontraksiyonunu koruyup, sol ventrikül duvar incelmesini azaltarak kardiyoprotektif etkiye yol açtığ gösterilmiştir $(12,13)$.

\section{1) Reseptör Olarak ACE2}

SARS-CoV pandemisi sırasında hastalığın patofizyolojisi üzerine yapılan çalışmalarda virusun ACE2'yi kullanarak hücre içine girdiği tespit edilmiştir. Yapılan çalışmalarda ACE2 ekspresyonunun azaltıldığ farelerde virus ile infeksiyon riski azalmaktadır (14). Bu sonuç SARS için ACE2 varlığının hayati olduğunu ortaya koymaktadır. Virus bağlandıktan sonra hücre yüzeyinde ACE2 ekspresyonu azalmaktadır. Bu azalma hücrede Ang2'nin Ang(1-7)'ye dönüşümünü azaltarak, Ang2'nin miktarını arttırmaktadır (15). Bu durum ACE2'nin klinik ve bilimsel önemini daha da arttırmıştır. 
Xudong ve arkadaşlarının SARS pandemisi sonrası farelerle yaptığı bir çalışmada, fareler 3 yaş grubuna ayrılarak yaşa ve cinsiyete göre akciğerlerindeki ACE2 ekspresyonu karşılaştırılmıştır. Fareler genç (3 ay), orta yaşlı (12 ay) ve yaşlı (24 ay) olarak üç gruba ayrılmış, immunhistokimya ve western blot yöntemiyle akciğer ACE2 ekspresyonları değerlendirilmiştir. $\mathrm{Bu}$ değerlendirme ile akciğerde ACE2 ekspresyonunun her iki cinsiyette de yaşla beraber azaldığı, genç ve orta yaş grubunda cinsiyetlere göre ACE2 ekspresyonunda belirgin fark saptanmazken yaşlı erkek farelerde kadın farelere göre ACE2 ekspresyonunda azalmanın daha belirgin olduğu bulunmuştur (16).

\section{2) ACE2 ve COVID-19}

ACE2'nin coronavirus alt tiplerinden NL63 ve SARS$\mathrm{CoV}$ için reseptör görevi gördüğü bilinmekteydi (17). COVID-19 pandemisiyle beraber SARS-CoV2'nin de hücreye girişte aynı reseptörü kullanması ACE2 molekülüne metabolik etkilerinin yanı sıra COVID-19 patogenezindeki rolü nedeniyle de önem kazandırmıştır. SARS-CoV ve SARS-CoV-2 yüzeylerinde bulunan $\mathrm{S}$ (spike) protein \%80 oranında benzerlik göstermekte ve her iki virus da S protein aracılığıyla ACE2 reseptörüne bağlanarak virüs endositozunu sağlamaktadır (18).

Xudong ve arkadaşlarının yaptığı çalışma (16) her ne kadar fare deneyi olsa da hem SARS hem de COVID-19'un klinik özellikleri göz önüne alındığında, hastalığın patofizyolojisini anlamak açısından önemli bir çalışmadır. COVID-19 ilişkili yaygın populasyon bazlı taramaların yapıldığı ülkelerden gelen verilerde, vakaların çoğunluğunun ACE2 düzeyinin yüksek olması beklenilen genç populasyonda görüldüğü fakat hastalığın ACE2 ekspresyonunun daha az olduğu yaşlılarda daha ağır seyrettiği gözlenmiştir (19). Bu durum göstermektedir ki ACE2 düzeyinin yüksekliği hastalığa yakalanma riskini artırmakta ve bu yüzden genç populasyon hastalığa daha fazla yakalanmaktadır. ACE2 düzeyinin az olduğu grupta hastalığın ağır seyretmesini açıklayabilecek en uygun mekanizma ise azalmış ACE2 düzeyinin yol açtığ1 artmış Ang2 düzeyi olabilir. Hücre yüzeyine bağlanan SARS-CoV-2, ACE2 ekspresyonunu daha da fazla baskılamakta ve lokal azalmış ACE2 düzeyi Ang2'nin Ang(1-7)'ye dönüşümünü azaltarak, karşılanmamış bir Ang2 baskınlığı yaratmaktadır (20).
Artmış Ang2 düzeyinin sistemik etkileri değerlendirildiğinde ağır seyreden COVID-19 vakalarıyla paralel bir klinik gözlemlenmektedir. SARS-CoV-2'nin en sık hedef aldığı organ akciğerdir ve akciğerde azalan ACE2'ye sekonder gelişen artmış Ang2'nin etkileri dikkat çekmektedir. RAAS'ın kan basıncı kontrolü ve kardiyovasküler sistem üzerindeki etkileri yaygın olarak bilinse de, akciğer de bu sistemin en etkin çalıştığı organlardan biridir. Öyle ki diğer organlarda kapiller endotellerin \%20'sinde ACE ekspresyonu varken, bu oran akciğerde \%100'e yakındır ve akciğerde bulunan yaygin ACE ekspresyonu bu organda Ang1'den Ang2'ye dönüşümü arttırmaktadır (21). COVID-19 seyrinde ve özellikle ARDS gibi durumlarda bozulmuş epitelyal ACE2 sekresyonuna sekonder Ang2 artışına karşı defans mekanizması bozulmakta ve akciğerde Ang2 baskınlığ1 oluşmaktadır. Ang2, AT1 ve AT2 reseptörleri aracılığıyla akciğerde pulmoner damarlarda vazokonstriksiyona yol açmakta ve artmış vasküler geçirgenlik hipoksik koşullarda pulmoner ödeme yol açmaktadır. Aynı zamanda akciğerde inflamatuvar sitokin salınımı ve apoptosis artmakta, ekstrasellüler matriks üretimi ise akciğer fibroproliferasyonuna yol açmaktadır (22). Buna karşın ARDS modellerinde yapılan çalışmalarda ACE2 ve Ang(1-7) oluşumunun ARDS kliniğinde koruyucu rol üstlendiği de bildirilmiştir (14).

SARS-CoV-2 'nin hedef organlarından birinin de endotel olduğu ve COVID-19 hastalarında endotelit görüldüğü bildirilmiştir (23). Ang2 endotel hücresinde inflamatuvar süreci ve vasküler remodelingi arttırmakta, hasarlı epitelyumda NO salınımını azaltarak endotelyal inflamasyon ve vazokonstriksiyonu şiddetlendirmektedir. Ayrıca pro-inflamatuvar bir sitokin olan Interlökin-6 (IL-6) düzeyi de Ang2 etkisi ile artmaktadır ki bu durum COVID-19 için kötü prognostik faktörlerden biri olarak gösterilmiştir (24). 
Özellikle ciddi seyirli COVID-19 hastalarında görülen bir diğer problem ise artmış prokoagülan aktivite olup bu hastalarda pulmoner emboli ile birlikte ekstrapulmoner mikrotrombozların da görüldüğü bildirilmiştir (25). COVID-19 hastalarında artmış Ang2 düzeyi, bu hastalardaki protrombotik sürecin de açılayıcısı olabilir. Artmış Ang2 düzeyleri doku faktörü (TF) ve plazminojen aktivatör inhibitör-1(PAI-1) düzeyini arttırmakta, büyük arterler vearteriollerde trombüs formasyonuna yol açmaktadır (26). Bir çalışmada, koagülasyon sürecini başlatmada temel faktör olan doku faktörü pozitif megakaryositler (TF-pozitif megakaryosit)'in hipertansif populasyonda normotansiflere göre sayıca daha fazla olduğu ve bu durumun daha hızlı ve daha büyük miktarda trombin oluşumuna yol açtığı saptanmıştır. Dahası bu hiperkoagülan sürecin endotel disfonksiyonuyla agreve olduğu fakat bir ACEI olan kaptopril ile azaldığı gözlenmiştir (27).

\section{RAAS Blokerleri ve COVID-19}

SARS-CoV-2'nin hücreye giriş reseptörü olarak ACE2'yi kullanması ve hastalığın kardiyovasküler komorbiditeleri olan yaşlı populasyonda ağır seyretmesi COVID-19 ve RAAS blokerleri arasında ilişkiyi merak konusu kılmıştır. RAAS blokeri kullanımının ACE2 ekspresyonuna etkisi üzerine çelişkili veriler mevcuttur. Hayvan modellerinde yapılan çalışmaların bir kısmında RAAS blokerlerinin dokularda ACE2 ekspresyonunu arttırdığı bulunurken, bazı çalışmalarda ise bu ilişki saptanamamıştır (28). RAAS blokeri kullanımına sekonder artmış ACE2 ekpresyonunun görüldüğü çalışmalar ise genellikle ACEI kullanımından ziyade ARB kullanımı üzerinedir $(29,30)$. Bu etkinin ARB grubunda daha belirgin olması ise patofizyolojik olarak şu şekilde açıklanabilir; ACE2, çoğunluğu membran yüzeyinde bulunan bir enzimdir ve kanda çözünür halde bulunan(solubl) ACE2 düzeyi oldukça düşüktür (31). SARS-CoV-2 hücreye girişte reseptör olarak membrana bağlı ACE2 molekülünü kullanmaktadır (32). Membran yüzeyindeki ACE2'nin parçalanıp solubl ACE2 formuna dönüşmesinde ADAM17 isimli metalloproteaz görev almaktadır. Anjiotensin 2, AT1 reseptörü aracilığıyla ADAM17 düzeyini ve neticesinde solubl ACE2 düzeyini arttırarak, membran yüzeyindeki ACE2'de azalmaya yol açacaktır (33). Dolayısıyla özellikle ARB kullanan hastalarda
AT1 reseptörü baskılanacağı için membran yüzeyinde bulunan ACE2 ekspresyonunda görece bir artı̧ meydana gelmesi beklenebilir $(32,34)$.

RAAS blokerleri ve ACE2 arasındaki ilişkiye dair çelişkili veriler olsa da bu ilaçları kullanan hastalarda ACE2 düzeyinde artma potansiyelinin, virusun hücreye girişini kolaylaştırabileceği ve hastalığın daha ağır geçirilmesine yol açabileceği hipotezi öne sürülmüştür (35). Dünya genelinde birçok kardiyovasküler hastalığın tedavisinde kullanılan bu ilaç grubunun üzerine düşen gölge, kafa karışıklıklarına sebep olmuş olsa da, yapılan çalışmalar bu endişeyi belli bir ölçüde gidermiştir. Farklı ülkelerde yapılan 11 gözlemsel çalışmanın hiç birinde ACEI ve ARB kullanımının COVID-19 geçirilme sıklığını ve şiddetini arttırdığına dair bir kanıta ulaşılamamıştır (36). Diğer solunum virusları ile yapılan hayvan çalışmaları ve klinik araştırmalarda ise ACEI ve ARB kullanımının potansiyel yararları gösterilmiştir (37). İlk bakışta bu ilaç gruplarının kullanılmasıyla artan ACE2 düzeyine sekonder virusla enfekte olma riski artiyor gibi görülse de Ang2'nin rol aldığ1 patofizyolojik süreçler düşünüldüğünde ACEI ve ARB kullanımının bu hastalarda zarardan çok fayda sağlaması beklenebilir.

$\mathrm{Bu}$ konuda yapılan birkaç farklı çalışma, bu ilaç gruplarının potansiyel faydalarını kanıtlar niteliktedir. Zhang ve arkadaşlarının yaptığı retrospektif bir kohort çalışmasında, Çin'de bulunan 8 farklı hastaneden alınan örneklemde, 1.128 hipertansiyon hastasının 188'i ACEI/ ARB kullanırken, 940'1 diğer antihipertansif ilaç gruplarını kullanmaktaydı. 
Hem primer sonlanım noktası olan 28 günlük mortalite, hem de sekonder sonlanım noktası olan septik şok ve Dissemine Intravasküler Koagülasyon (DİK) tablosu ACEI/ ARB kullanan grupta daha düşük saptanmıştır (38). Bu çalışma her ne kadar bazı yöntemsel kısıtlılıklara sahip olsa da ACEI/ARB'lerin COVID-19 hastalarında potansiyel yararını göstermekte önemlidir. ACEI/ARB kullanan 17 hasta ile diğer antihipertansifleri (kalsiyum kanal blokeri, beta bloker ve diüretikler) kullanan 25 hastanın karşılaştırıldığı bir çalışmada ise semptom başlangıcı ve hospitalizasyon arası geçen süre ACEI/ARB grubunda ortalama 4 gün iken, diğer grupta 2 gün olarak saptanmıştır. Her iki grupta ortalama hastane yatış süresi arasında anlamlı fark görülmemiştir. ACEI/ARB kullanan hastalarda ağır hastalık ve ölüm oranları diğer gruba göre daha düşük saptanmıştır. ACEI/ARB kullananların \%23'ü (4 hasta) ağır hastalık grubunda iken bu hastalarda hiç ölüm görülmemiştir. Diğer antihipertansifleri kullanan hastaların ise \%48'inin (12 hasta) ağır hastalık grubunda olduğu saptanmış, sadece bir ölüm görülmüştür. Ancak bu fark, vaka sayısının azlığı nedeniyle istatistiksel olarak bir anlam ifade etmemektedir. Ayrıca ACEI/ ARB grubunda, IL-6 düzeyi daha düşük, CD3+ ve CD8+ T lenfosit düzeyi daha yüksek saptanmıştır. Saptanan ilginç bir sonuç ise başlangıçta her iki grupta viral yük aynı olmasına karşın, hastane yatışı sırasında pik viral yük, ACEI/ARB kullanan grupta daha düşük saptanmıştır. $\mathrm{Bu}$ durum RAAS blokerlerinin immünomodülatör etkisi aracılığıyla viral yükü azaltmada dolaylı yoldan katkısının olabileceği ile ilişkilendirilmişstir (39).

Madrid'de 1139 vaka ve 11390 kontrol ile yapılan çok merkezli bir çalışmada; kısa dönem $(<1$ yıl $)$ veya uzun dönem(>1 yıl) RAAS blokerleri kullanımının hastaneye yatışı arttırmadığı saptanmıştır. Çalışmada bulunan dikkate değer sonuç ise diyabetik hasta grubu özelinde RAAS blokeri kullanımının hastaneye yatışı azalttığıdır. Deneysel modellerde diyabetik farelerde akciğerde artmış ACE aktivasyonu gözlemlenmiştir. Bu durum insanlara uyarlandığında, COVID-19 tanılı diyabetik hastalarda ACE:ACE2 oranının(diyabete sekonder artmış ACE ve SARS-CoV'ye sekonder azalmış ACE2 ekspresyonu) artmış olabileceği ve RAAS blokerlerinin bu grupta koruyuculuğunun buna bağlı olabileceği düşünülmüştür (40).

\section{Sonuç}

COVID-19 ve RAAS ilişkisi halen gizemini korumaktadır. Bugüne kadar yapılan hiçbir çalışmada ACEI/ ARB kullanımının hastalık seyrini kötüleştirdiğine dair bir kanıtın saptanamamış olması, bu ilaçların üzerindeki endişeyi büyük ölçüde kaldırmıştır. Ang2'nin metabolik ve fizyolojik etkileri ile SARS'taki tecrübeler göz önüne alındığında ve hastalığın klinik seyri düşünüldüğünde COVID-19 patogenezinde RAAS'ın düşünülenden daha etkin olabileceği görülmektedir. ACEI/ARB kullanımının hastalık seyrinde potansiyel faydaları birkaç küçük çalışmada gösterilse bile bu konu ile ilgili daha fazla sayıda randomize kontrollü çalışmalara ihtiyaç vardır. 
1. Türkiye Cumhuriyeti Sağlık Bakanlığı Halk Sağlığ1 Genel Müdürlüğü. Erişim tarihi: 14 Nisan 2020. Available from: https://hsgm.saglik.gov.tr/tr/covid19

2. Leung, Char. "Clinical features of deaths in the novel coronavirus epidemic in China." Reviews in Medical Virology 2020: e2103.

3. Wan Y, Shang J, Graham R, Baric RS, Li F. Receptor Recognition by the Novel Coronavirus from Wuhan: an Analysis Based on Decade-Long Structural Studies of SARS Coronavirus. J Virol. 2020;94:e00127-20.

4. Hasöksüz, Mustafa, Selçuk Kiliç, and Fahriye Saraç. Coronaviruses and SARS-CoV-2. Turkish Journal of Medical Sciences 50.SI-1 2020:549-56.

5. World Healt Organization. WHO. Novel Coronavirus (2019-nCoV) situation report - 10. Data as reported by 30 January 2020. Avaible from: https://www. who.int/docs/default-source/coronaviruse/situation-reports/20200130-sitrep-10-ncov.pdf?sfvrsn=d0b2e480_2.

6. Donoghue $\mathrm{M}$, Hsieh F, Baronas E, et al. A novel angiotensin-converting enzyme-related carboxypeptidase (ACE2) converts angiotensin I to angiotensin 1-9. Circ Res. 2000;87:E1-E9.

7. Patel, Sheila K., et al. From gene to protein-experimental and clinical studies of ACE2 in blood pressure control and arterial hypertension. Frontiers in physiology, 2014,5: 227.

8. Tipnis SR, Hooper NM, Hyde R, Karran E, Christie G, Turner AJ. A human homolog of angiotensin-converting enzyme. Cloning and functional expression as a captopril-insensitive carboxypeptidase. J Biol Chem. 2000;275:33238-43.

9. Hamming I, Timens W, Bulthuis ML, Lely AT, Navis $\mathrm{G}$, van Goor H. Tissue distribution of ACE2 protein, the functional receptor for SARS coronavirus. A first step in understanding SARS pathogenesis. J Pathol. 2004;203:631-7.

10. Crackower MA, Sarao R, Oudit GY, et al. Angiotensin-converting enzyme 2 is an essential regulator of heart function. Nature. 2002;417:822-8.

11. Zisman LS, Keller RS, Weaver B, et al. Increased angiotensin-(1-7)-forming activity in failing human heart ventricles: evidence for upregulation of the angiotensin-converting enzyme Homologue ACE2. Circulation. 2003 Oct;108:1707-12
12. Burrell LM, Risvanis J, Kubota E, et al. Myocardial infarction increases ACE2 expression in rat and humans. Eur Heart J. 2005;26:369-324.

13. Der Sarkissian S, Grobe JL, Yuan L, et al. Cardiac overexpression of angiotensin converting enzyme 2 protects the heart from ischemia-induced pathophysiology. Hypertension. 2008;51:712-8.

14. Kuba $K$, Imai $Y$, Rao $S$, et al. A crucial role of angiotensin converting enzyme 2 (ACE2) in SARS coronavirus-induced lung injury. Nat Med. 2005;11:875-9.

15. Imai $Y$, Kuba K, Rao S, et al. Angiotensin-converting enzyme 2 protects from severe acute lung failure. Nature. 2005;436:112-6.

16. Xie X, Chen J, Wang X, Zhang F, Liu Y. Age- and gender-related difference of ACE2 expression in rat lung [published correction appears in Life Sci. 2006 Nov 25;79:2499.

17. Jia HP, Look DC, Shi L, et al. ACE2 receptor expression and severe acute respiratory syndrome coronavirus infection depend on differentiation of human airway epithelia. J Virol. 2005;79:14614-21.

18. Kai $\mathrm{H}$, Kai $\mathrm{M}$. Interactions of coronaviruses with ACE2, angiotensin II, and RAS inhibitors-lessons from available evidence and insights into COVID-19. Hypertens Res. 2020;43:648-54.

19. Backhaus A. Coronavirus: why it's so deadly in Italy. Demographics and why they are a warning to other countries. Medium, 13 March 2020. Available from: https:// medium.com/@andreasbackhausab/coronavirus-why-itsso-deadly-in-italy-c4200a15a7bf

20. AlGhatrif M, Cingolani O, Lakatta EG. The Dilemma of Coronavirus Disease 2019, Aging, and Cardiovascular Disease: Insights From Cardiovascular Aging Science [published online ahead of print, 2020 Apr 3]. JAMA Cardiol. 2020;10.1001/jamacardio.2020.1329.

21. Metzger R, Franke FE, Bohle RM, Alhenc-Gelas F, Danilov SM. Heterogeneous distribution of angiotensin I-converting enzyme (CD143) in the human and rat vascular systems: vessel, organ and species specificity. Microvasc Res. 2011;81:206-15

22. Zhang $\mathrm{H}$, Baker A. Recombinant human ACE2: acing out angiotensin II in ARDS therapy. Crit Care. 2017;21:305

23. Varga Z, Flammer AJ, Steiger P, et al. Endothelial cell infection and endotheliitis in COVID-19. Lancet. 2020;395:1417-8.

24. Watanabe T, Barker TA, Berk BC. Angiotensin II and the endothelium: diverse signals and effects. Hypertension. 2005;45:163-9. 
25. Zhang T, Sun LX, Feng RE. [Comparison of clinical and pathological features between severe acute respiratory syndrome and coronavirus disease 2019]. Zhonghua jie he he hu xi za zhi = Zhonghua Jiehe he Huxi Zazhi = Chinese Journal of Tuberculosis and Respiratory Diseases. 2020;43:496-502

26. Senchenkova EY, Russell J, Almeida-Paula LD, Harding JW, Granger DN, Angiotensin II-mediated microvascular thrombosis. Hypertension. 2010; 56:1089-95.

27. Brambilla M, Gelosa $P$, Rossetti L, et al. Impact of angiotensin-converting enzyme inhibition on platelet tissue factor expression in stroke-prone rats. J Hypertens. 2018;36:1360-71.

28. Vaduganathan, Muthiah, et al. Renin-angiotensinaldosterone system inhibitors in patients with Covid-19. New England Journal of Medicine, 2020, 382.17: 1653-9. 29. Ferrario, Carlos M., et al. Effect of angiotensin-converting enzyme inhibition and angiotensin II receptor blockers on cardiac angiotensin-converting enzyme 2 . Circulation, 2005, 111.20: 2605-10.

30. Wang, Xingxu, et al. The effects of different angiotensin II type 1 receptor blockers on the regulation of the ACE-AngII-AT1 and ACE2-Ang (1-7)-Mas axes in pressure overload-induced cardiac remodeling in male mice. Journal of molecular and cellular cardiology, 2016, 97:180-90.

31. Serfozo, Peter, et al. Ang II (angiotensin II) conversion to angiotensin-(1-7) in the circulation is POP (prolyloligopeptidase)-dependent and ACE2 (angiotensin-converting enzyme 2)-independent. Hypertension, 2020, 75.1: 173-82.

32. Danser AHJ, Epstein M, Batlle D. Renin-Angiotensin System Blockers and the COVID-19 Pandemic: At Present There Is No Evidence to Abandon Renin-Angiotensin System Blockers. Hypertension 2020;75:1382-5.

33. $\mathrm{Xu}$, Jiaxi, et al. Clinical relevance and role of neuronal AT1 receptors in ADAM17-mediated ACE2 shedding in neurogenic hypertension. Circulation research, 2017, 121.1: 43-55.

34. Esler, Murray; Esler, Danielle. Can angiotensin receptor-blocking drugs perhaps be harmful in the COVID-19 pandemic? Journal of hypertension, 2020, 38.5: 781-2

35. Fang L, Karakiulakis G, Roth M. Are patients with hypertension and diabetes mellitus at increased risk for COVID-19 infection? [published correction appears in Lancet Respir Med. 2020 Jun;8(6):e54]. Lancet Respir Med. 2020;8:e21
36. WHO, COVID-19 and the use of angiotensin-converting enzyme inhibitors and receptor blockers, Scintific Brief, 07 MAY 2020, Avaliable from: https://www.who. int/news-room/commentaries/detail/covid-19-and-theuse-of-angiotensin-converting-enzyme-inhibitors-andreceptor-blockers)

37. Kuster GM, Pfister O, Burkard T, et al. SARSCoV2: should inhibitors of the renin-angiotensin system be withdrawn in patients with COVID-19?. Eur Heart J. 2020;41:1801-3.

38. Zhang $\mathrm{P}, \mathrm{Zhu} \mathrm{L}$, Cai J, et al. Association of Inpatient Use of Angiotensin-Converting Enzyme Inhibitors and Angiotensin II Receptor Blockers With Mortality Among Patients With Hypertension Hospitalized With COVID-19. Circ Res. 2020;126:1671-81.

39. Meng J, Xiao G, Zhang J, et al. Renin-angiotensin system inhibitors improve the clinical outcomes of COVID-19 patients with hypertension. Emerg Microbes Infect. 2020;9:757-60.

40. De Abajo FJ, Rodríguez-Martín S, Lerma V, et al. Use of renin-angiotensin-aldosterone system inhibitors and risk of COVID-19 requiring admission to hospital: a case-population study. Lancet. 2020;395:1705-14. 